\title{
Calcinosis Cutis Long after Rhinoplasty with Silicone
}

\author{
Yuki Honda Hideaki Tanizaki Atsushi Otsuka Yoshiki Miyachi \\ Kenji Kabashima
}

Department of Dermatology, Kyoto University Graduate School of Medicine, Kyoto, Japan

\section{Key Words}

Calcinosis cutis · Rhinoplasty · Silicone

\begin{abstract}
Rhinoplasty is a plastic surgery procedure to reconstruct the nose. Silicone alloplastic materials are most widely used as implants for rhinoplasty, but calcification on the surface occurs with long-term usage. Herein, we report a case of gruel-like calcification approximately 50 years after silicone implant rhinoplasty. In this case, calcification on the silicone surface might have transformed into gruel-like deposits, which presented as a subcutaneous mass at the dorsal area of the nose. The precise mechanism is unclear; a pH change in the tissue might have occurred during the process of inflammation, leading to the dissolution of calcified deposits.

(C) 2014 S. Karger AG, Basel
\end{abstract}

\section{Introduction}

Rhinoplasty is a plastic surgery procedure that is employed to reshape the nose, often through the use of implants. Implants for reconstruction are divided into two main material types: autogenous and alloplastic. Alloplastic materials are composed of silicone and other synthetic materials. Since alloplastic materials are cheaper and easier to acquire and process, they are used more frequently. However, alloplastic materials, especially silicone, lead to a higher risk of extrusion and infection [1]. In addition, calcification on the surface of silicone implants after rhinoplasty with transformation into a semiliquid form has been reported to be quite rare [2]. Herein, we report a case of gruel-like calcification about 50 years after silicone implant rhinoplasty. 
Honda et al.: Calcinosis Cutis Long after Rhinoplasty with Silicone

\section{Case Report}

A 72-year-old female presented at our hospital with complaints of progressive swelling of the nose. She had noticed mild pruritic sensations of the nose 1 year earlier, and the dorsal area of the nose had then swollen gradually without any other symptoms. She had a history of rhinoplasty with silicone implant approximately 50 years earlier.

Upon physical examination, we found a subcutaneous mass, $15 \times 5 \mathrm{~mm}$ in size, at the dorsal nasal area (fig. 1a). The mass was elastic-hard without tenderness. A superficial ultrasound test showed a well-circumscribed subcutaneous mass with post-acoustic shadow, which indicated calcification therein (fig. 1b). X-ray and ultrasound tests showed a highintensity plate over the dorsal nasal area (fig. 1c), indicating the silicone plate placed in her nose. Based on the clinical manifestation, the differential diagnosis included calcinosis cutis, calcifying epithelioma, foreign body granuloma and subcutaneous tumors.

To confirm a diagnosis, we took a skin biopsy. A white, gruel-like, semiliquid material seeped out and solidified shortly thereafter. Histological analysis of this white gruel-like semiliquid material confirmed calcified deposits and fibrosis (fig. 1d). There were no foreign body giant cells or malignant cells. From the above findings, we considered the calcified deposits to be a possible result of rhinoplasty using silicone.

\section{Discussion}

In this case, we observed gruel-like, semiliquid calcified deposits, probably related to the long-term use of a silicone implant. Silicone is a widely used rhinoplasty material that is chemically stable and has low biological reactivity, but in this case, calcification at the surface of the implant appears to have occurred after approximately 50 years. It has been reported that the severity of calcification is correlated with the duration of use, and that a denatured type of large calcification can be observed in silicone implants older than 15 years [2]. Calcification on the surface of the implant after rhinoplasty often occurs, but to the best of our knowledge, this is the first report of it transforming into a semiliquid state.

Although the precise mechanism of calcification on the surface of implants is unclear, silicone-rich surfaces are more likely to be calcified compared to non-silicone implants [3]. In addition, long-term mechanical stress and inflammatory reactions might be responsible for calcification, namely the deposition of calcium phosphate [4]. It is difficult for calcium phosphate to dissolve under normal conditions, but it dissolves easily in a low-pH environment. In inflammatory lesions, tissue $\mathrm{pH}$ decreases locally due to the increased production of lactic acid, which is related to tissue damage and bacterial metabolism [5].

In our case, calcification at the surface of the silicone implant was observed after approximately 50 years of use. The patient had pruritus before the formation of a subcutaneous mass at the dorsal nasal area, which is indicative of inflammation occurring at the site. Although the underlying mechanism remains unclear, a $\mathrm{pH}$ change in the tissue might have occurred during the process of inflammation that resulted in the dissolution of calcified deposits.

\section{Disclosure Statement}

The authors report no conflict of interest or financial support. 


\section{Case Reports in Dermatology}

\begin{tabular}{l|l}
\hline Case Rep Dermatol 2014;6:288-290 \\
\hline DOI: 10.1159/000370304 & $\begin{array}{l}\text { C 2014 S. Karger AG, Basel } \\
\text { www.karger.com/cde }\end{array}$ \\
\hline
\end{tabular}

Honda et al.: Calcinosis Cutis Long after Rhinoplasty with Silicone

\section{References}

1 Berghaus A: Implants for reconstructive surgery of the nose and ears. GMS Curr Top Otorhinolaryngol Head Neck Surg 2007;6:Doc06.

-2 Jung DH, Kim BR, Choi JY, Rho YS, Park HJ, Han WW: Gross and pathologic analysis of long-term silicone implants inserted into the human body for augmentation rhinoplasty: 221 revision cases. Plast Reconstr Surg 2007;120:1997-2003.

-3 Peters WSD, Lugowski S, Pritzker K, Holmyard D: Calcification properties of saline-filled breast implants. Plast Reconstr Surg 2001;107:356-363.

-4 Kossovsky N, Freiman CJ: Silicone breast implant pathology. Clinical data and immunologic consequences. Arch Pathol Lab Med 1994;118:686-693.

5 Lardner A: The effects of extracellular pH on immune function. J Leukoc Biol 2001;69:522-530.
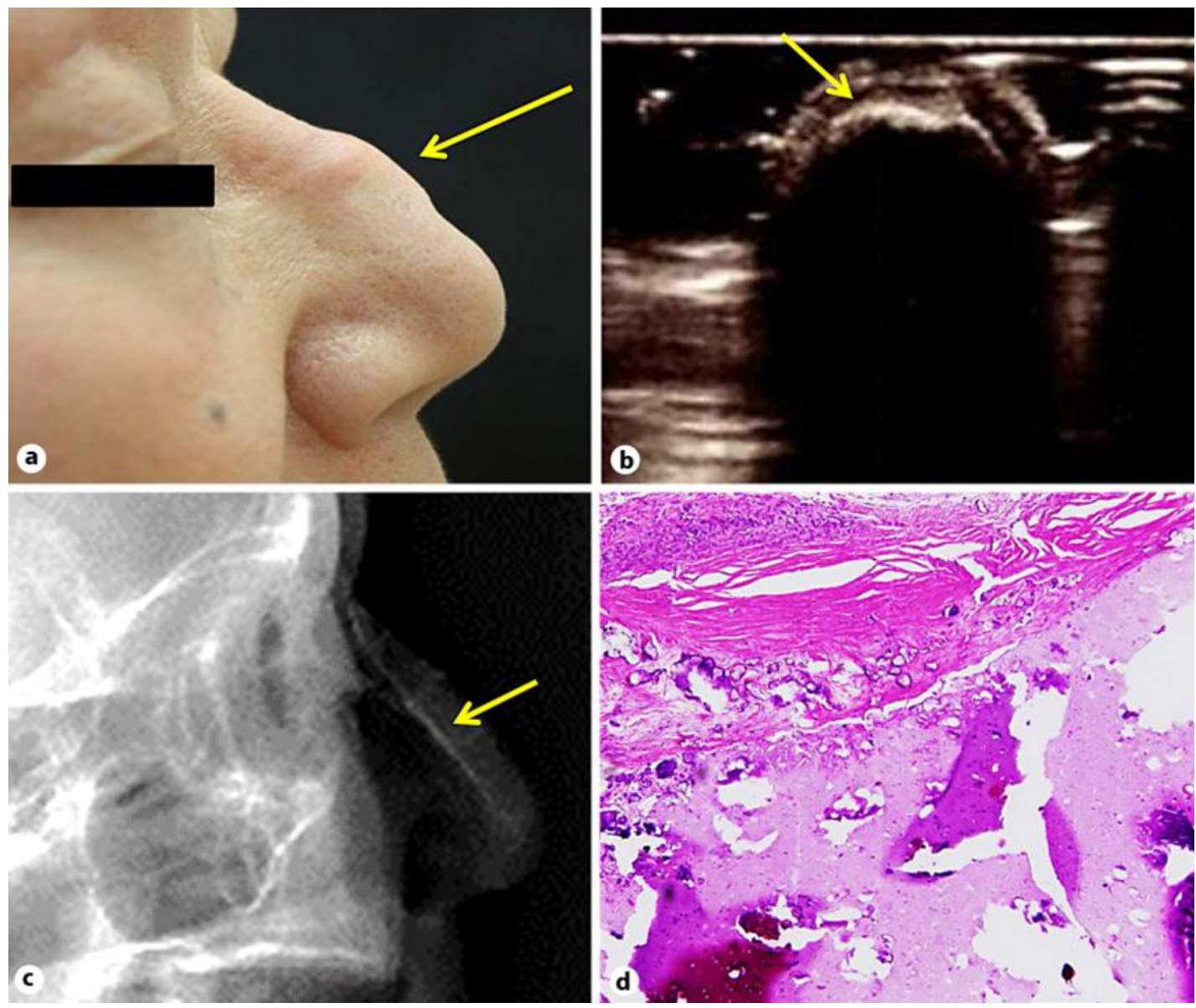

Fig. 1. Clinical appearance and pathological findings. a Subcutaneous mass of the nasal dorsal area $(15 \times$ $5 \mathrm{~mm}$ in size) that was asymptomatic and free of skin discoloration (arrow). b Superficial ultrasound test showed a subcutaneous mass with post-acoustic shadow (arrow). c X-ray image showed a high-intensity plate over the nasal dorsal area (arrow). $\mathbf{d}$ Histopathology demonstrating calcified deposits in the dermis and subcutaneous tissue with peripheral fibrosis $(\mathrm{H} \& \mathrm{E}, \times 10)$. 